\title{
Modeling thermal interactions between buildings in urban context
}

\author{
Xuan Luo ${ }^{1}$, Tianzhen Hong ${ }^{1}$ \\ ${ }^{1}$ Lawrence Berkeley National Laboratory, Berkeley, California, USA
}

\begin{abstract}
Understanding the thermal interactions between buildings and environment is one key factor in urban modeling and simulation, as they can strongly influence buildings' energy use, environmental impact and occupants' thermal comfort. We added a new feature to EnergyPlus in version 8.8.0, modifying the heat balance of the building's exterior surfaces to explicitly consider these effects. We conducted a case study with a district in the Chicago downtown area applying the feature, simulating and evaluating the heat exchange effects between the exterior surfaces of those high-rise buildings. Results show the radiant heat exchange between buildings have impacts on buildings' energy demand and heat emissions to ambient, especially in the dense urban areas.
\end{abstract}

\section{Introduction}

Urbanized areas account for $67 \sim 76 \%$ of the global primary or final energy consumption (Guneralp et al. 2017). By 2014, more than half of the world's population lived in urban areas and by $2020,66 \%$ of the world's population is projected to be urban (UNDESA, 2014). As buildings consume up to $70 \%$ of the primary energy use in cities, cities are paying greater attention to building energy efficiency in urban planning, and in meeting city goals for reduction of GHG emissions ( $\mathrm{Li}$ et al., 2017). In dense urban areas, the urban context, including the surrounding buildings and their direct individual effects on a building (e.g., urban heat island effect) can strongly influence the building's energy use and demand.

As much as the impact of thermal performance of buildings as an individual is well documented in general building energy simulation tools, the thermal interactions between buildings are generally less understood or considered (Cole, 1976). In the urban context, radiant heat exchange occurs between buildings' exterior surfaces and (1) the sky, (2) the ground, and (3) other surfaces, including other buildings' exteriors surfaces, wet land, vegetation cover, tree, etc. Among these, the thermal interconnections between buildings mainly occur via the longwave radiant (LWR) heat exchange between buildings' exterior surfaces.

Literature has introduced different methodologies to calculate and simulate the thermal interactions between buildings. Work by Evins et al. coupled EnergyPlus with the microclimate tool, ENVI-Met, to improve the longwave exchange process of building energy modeling considering other building surfaces (Evins, Dorer, \& Carmeliet, 2014). The case study results indicated that the combined impact of street canyon and shading devices led to an increase in surface temperature of up to $6^{\circ} \mathrm{C}$, a decrease in annual heating load of $18 \%$, and an increase in cooling load of $19 \%$. A similar study by Miller et al. implemented the longwave radiation exchange as part of a co-simulation process of an urban scale simulation program, CitySim, and EnergyPlus (Miller \& Baker, 2016). They used functional mockup units (FMU) to exchange various weather, load, and environmental information between the two simulation engines. In urban microclimate studies, Gros et al. computed the longwave irradiance exchanged between each urban surface through a linear model to demonstrate the impact of longwave irradiation on urban greenhouse effect (Gros, Bozonnet, Inard, \& Musy, 2016).

Urban building energy modeling (UBRM) tools have been developed to simulate an urban district taking into account of urban microclimate and energy flow between buildings for planning purposes. Previous researches have presented several approaches of the treatment of external LWR exchange in urban energy modeling. They have developed algorithms and tools to address the need of modeling building energy in an urban context, taking the surrounding buildings into consideration. Jones and Greenberg have introduced the method of pixel counting combined with B-spline surface interpolation for calculating direct solar gains on architectural CAD models (Jones \& .Greenberg, 2011). Hoover and Dogan have also presented the pixel counting algorithm for external solar shading calculation, addressing its weakness of high comuptational costs in existing simulation tools (Hoover \& Dogan, 2017). Similarly, Jones et al. have presented the ray casting method of 
calculating view factors between two urban surfaces, which is faster than the commonly used geometric analogy way (Jones, McCrone, Walter, Pratt, \& Greenberg, 2013). The simulation engines, such as EnergyPlus, can take advantage of these advanced and robust algorithms by integrating the external calculation results into their simulation.

EnergyPlus (Crawley et al., 2001) is the U.S. Department of Energy's flagship building energy software for simulating the dynamic energy and environmental performance of buildings. An EnergyPlus model calculates a building's thermal loads, system response to those loads, and resulting energy use, along with related metrics like occupant comfort and energy costs. Applied to urban energy modeling, EnergyPlus calculates the overall thermal behavior of the urban buildings in terms urban boundary conditions (i.e. exterior surface temperatures) and the heat and airflow exchange with the urban environment (Hong \& Luo, 2018). Yet in older versions, EnergyPlus models buildings as standalone entities and physical processes. Traditionally in EnergyPlus, calculations for LWR heat exchange between exterior surfaces and their surrounding surfaces were over-simplified, considering only the radiative heat exchange from and to the sky and the ground. However, in a dense urban setting with lots of high-rise building, these effects can be large and can have a significant impact on building performance. Thus, this simplification is causing potential under or over-estimate of exterior surface temperatures. Explicitly considering the thermal interconnections between buildings in an urban context requires simulation engines to evolve to incorporate this new information into calculations and to do in a scalable way that achieves feasible computing performance and accuracy for urban scale applications.

This paper presents the features implemented in EnergyPlus version 8.8 that improve its accuracy in an urban context by considering thermal interactions between buildings and expand its applicability to urban scale building energy simulation. The feature is introduced along with simulation examples to demonstrate its use and impact. The study addresses the need of taking explicit consideration of the thermal interactions between urban surfaces in a dense urban setting with lots of high-rise buildings. Used in urbanscale modeling applications, this new feature enables modeling the urban canyon effect, which also influences the building's energy demand and indoor occupant thermal comfort. The study also shows much greater computing resource is required to apply this feature into a larger spatial scale of urban building energy simulation and coupled multiscale urban systems.

\section{Thermal Interactions between Buildings}

Modeling longwave radiant heat exchange between buildings in EnergyPlus

Old versions of EnergyPlus assumed that the temperatures of exterior surfaces of different buildings are essentially uniform and that long-wave radiant exchange between them is negligible. With this assumption, the surface heat balance equation was simplified as:

$$
\begin{gathered}
\mathrm{q}_{\mathrm{LWR}}=\varepsilon \sigma\left[\mathrm{F}_{\text {sky }}\left(\mathrm{T}_{\text {sky }}^{4}-\mathrm{T}_{\text {surf }}^{4}\right)+\mathrm{F}_{\mathrm{a}}\left(\mathrm{T}_{\mathrm{a}}^{4}-\mathrm{T}_{\text {surf }}^{4}\right)\right. \\
\left.+\mathrm{F}_{\mathrm{g}}\left(\mathrm{T}_{\mathrm{g}}^{4}-\mathrm{T}_{\text {surf }}^{4}\right)\right]
\end{gathered}
$$

Where:

$\varepsilon=$ long - wave emittance of the surface,

$\sigma=$ Stefan - Boltzmann constant $\left(\mathrm{W} \cdot \mathrm{m}^{-2} \cdot \mathrm{K}^{-4}\right)$,

$\mathrm{T}_{\text {surf }}=$ Outside temperature of the surface $\left({ }^{\circ} \mathrm{C}\right)$,

$\mathrm{T}_{\text {sky }}=$ Sky temperature $\left({ }^{\circ} \mathrm{C}\right)$,

$\mathrm{F}_{\text {sky }}=$ View factor of the sky,

$\mathrm{T}_{\mathrm{g}}=$ Ground temperature $\left({ }^{\circ} \mathrm{C}\right)$,

$\mathrm{F}_{\mathrm{g}}=$ View factor of the ground,

$\mathrm{T}_{\mathrm{a}}$

$=$ Outside temperature of surrounding surface $\mathrm{i}\left({ }^{\circ} \mathrm{C}\right)$,

$\mathrm{F}_{\mathrm{a}}=$ View factor of surrounding surface $\mathrm{i}$.

In many urban contexts, specifically in the presence of urban canyons - relatively narrow streets with tall, continuous buildings on both sides of the roads - this assumption is flawed in two aspects. First, in a dense urban area, the view factors of a building façade to surrounding buildings' façades are not neglectable, and the surface temperature of the surrounding façades can be much higher than the sky or ground temperature. Second, in different time of a day, a building's surfaces temperature of different façade orientations can deviate each other to a couple of degree Celsius (Gros, Bozonnet, \& Inard, 2014). As the north façade of a building often faces the south facade of its surrounding buildings, under different circumstance, some exterior zones may be absorbing heat from longwave radiation, while other zones are losing heat to the ambient.

Considering this, we modified the EnergyPlus code to optionally considere the longwave radiant heat exchange to and from buildings' nearby surfaces (i.e., surrounding buildings' exterior surfaces, water bodies, green lands, 
etc.) in addition to the radiation from sky and ground as currently considered (Figure 1).

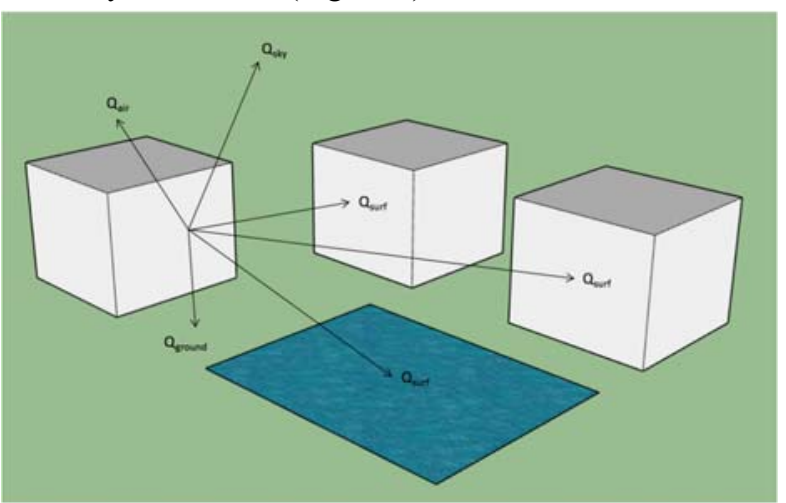

Figure 1: Long-wave radiation calculation considering surrounding surfaces.

In the modified model implementation, the energy balance of an exterior building surface from the sky, air, ground, and surrounding surfaces is written as:

$$
\begin{aligned}
\mathrm{q}_{\mathrm{LWR}}=\varepsilon \sigma\left[\mathrm{F}_{\text {sky }}\right. & \left(\mathrm{T}_{\text {sky }}^{4}-\mathrm{T}_{\text {surf }}^{4}\right) \\
& +\mathrm{F}_{\mathrm{a}}\left(\mathrm{T}_{\mathrm{a}}^{4}-\mathrm{T}_{\text {surf }}^{4}\right)+\mathrm{F}_{\mathrm{s} 1}\left(\mathrm{~T}_{\mathrm{s} 1}^{4}-\mathrm{T}_{\text {surf }}^{4}\right) \\
& +\mathrm{F}_{\mathrm{s} 2}\left(\mathrm{~T}_{\mathrm{s} 2}^{4}-\mathrm{T}_{\text {surf }}^{4}\right)+\cdots \\
& +\mathrm{F}_{\text {sn }}\left(\mathrm{T}_{\mathrm{sn}}^{4}-\mathrm{T}_{\text {surf }}^{4}\right) \\
& \left.+\mathrm{F}_{\mathrm{g}}\left(\mathrm{T}_{\mathrm{g}}^{4}-\mathrm{T}_{\text {surf }}^{4}\right)\right]
\end{aligned}
$$

Where:

$\mathrm{T}_{\text {si }}$

$=$ Outside temperature of surrounding surface $\mathrm{i}\left({ }^{\circ} \mathrm{C}\right)$,

$F_{s i}=$ View factor of surrounding surface $i$.

And the sum of all view factors equals one, i.e., $\mathrm{F}_{\text {sky }}+$ $\mathrm{F}_{\mathrm{s} 1}+\cdots+\mathrm{F}_{\mathrm{sn}}+\mathrm{F}_{\mathrm{g}}=1$.

Heat-balance equations are solved iteratively within each time step, resulting in small updates to surface and air temperatures until convergence criteria are met. Because the number of surfaces from other buildings can be large, an iterative solution method can add significant runtime. To avoid this complexity, for surrounding surfaces, we use a fixed temperature $\mathrm{T}_{\mathrm{si}}$, specifically the one calculated by the previous time step. Effectively, we assume one time step worth of "lag" for exterior surface temperatures. This simplification may sacrifice some accuracy but significantly improves computing performance.

To each exterior surface, we assign a "surrounding surfaces" object. The object declares a list of surrounding surfaces, and each surface has a name, a constant view factor, and a reference to a temperature schedule. If EnergyPlus is used in "co-simulation" or "urban-scale" mode to simulate multiple buildings in parallel, the schedule can be overwritten at each time step via the co-simulation interface.

\section{Modeling urban buildings and their surrounding surfaces}

We use the CityBES platform to model the buildings in an urban context. CityBES is an open and free data and computing web platform which uses CityGML-based 3D city models to simulates building performance at urban scale, adopting EnergyPlus and Openstudio as its simulation cores (Hong, Chen, Lee, \& Piette, 2016). CityBES models the neighborhood buildings as shading surfaces in EnergyPlus to consider the solar overshadowing effect between buildings (Chen, Hong, \& Piette, 2017). We adopt the shading surfaces defined in CityBES as a building's surrounding surfaces. For each exterior surface, we consider all shading surfaces with the opposite orientation as surrounding surfaces, and calculate their view factors to the exterior surface for radiant heat exchange calculation. Although surrounding surfaces from other orientations may also have longwave radiative effect, the impacts can be neglectable, as the view factors from those surfaces should be considerably small.

Figure 2 shows the 3D visualization of a building model along with its surrounding buildings (grey surfaces).
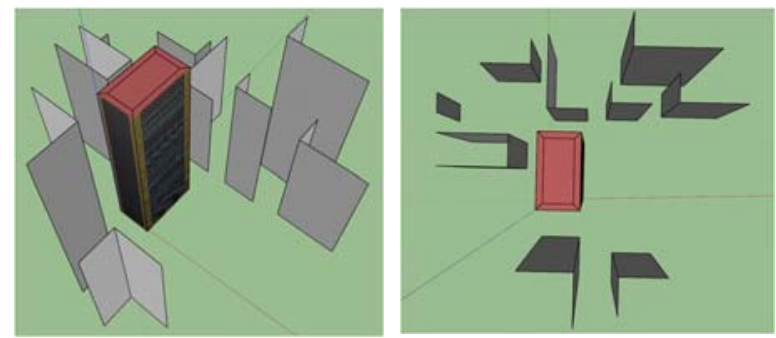

Figure 2: Building model and its surrounding surfaces.

\section{View factors of obstructive surrounding surfaces}

We adopted the View3D as the tool for evaluating radiation view factors between two 3D surfaces. View3d uses an adaptive integration method to calculate the view factors between faces where there is partial obstruction from in-between faces. Double Area Integration formula is used to calculate the view factors between two planar surfaces (i.e., surface $1 \& 2$ ), and the fundamental expression is written as:

$$
A_{1} F_{12}=\iint_{A_{1} A_{2}} \frac{\left(d A_{1} \cos \theta_{1}\right)\left(d A_{2} \cos \theta_{2}\right)}{\pi r^{2}}
$$

where $A_{1}$ and $A_{2}\left(\mathrm{~m}^{2}\right)$ are the areas of surfaces 1 and 2; $\theta_{1}$ and $\theta_{2}\left({ }^{\circ}\right)$ are the angles between the normals to surface differential elements $\mathrm{dA}_{1}$ and $\mathrm{dA}_{2}$ and the vector between those differential elements; $r$ is the length of that vector (Walton, 1986). When a third surface is added between two planar surfaces, the programs calculates the 
blockage factor by tracing the rays between each two differential elements $\mathrm{dA}_{1}$ and $\mathrm{dA}_{2}$.

\section{Simulation Examples}

\section{Simulation settings}

We chose a city block in the Chicago downtown area with highly dense high-rise buildings to conduct a case study, as shown in Figure 3. The block contains 20 buildings, of which 14 are office buildings and six are hotel buildings. The target building for LWR effect analysis, marked in the figure, is a fifty-seven-story large hotel, shaded by surrounding high-rise buildings in three facades. The geometry of the EnergyPlus building model and surrounding surfaces are visualized in Figure 2.

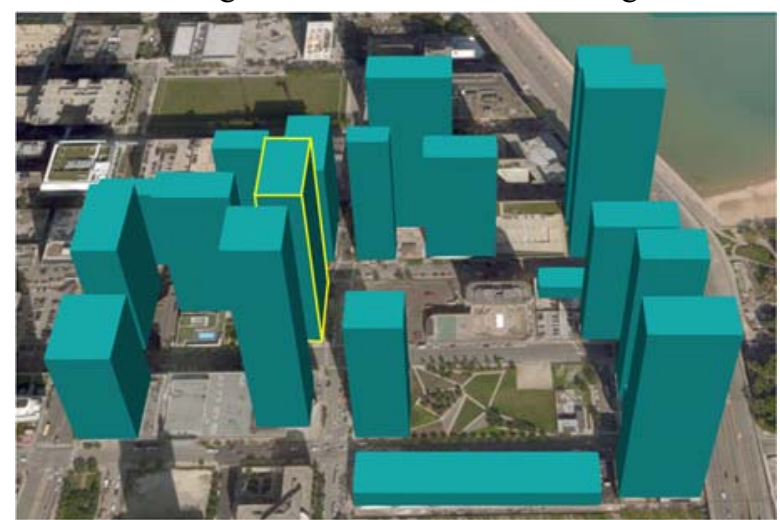

Figure 3: A sample city block in Chicago Loop area with 20 buildings.

To evaluate the energy impact of the radiant heat exchange, we first ran each EnergyPlus building model individually and independently without considering inputs from other buildings, and output their hourly exterior surfaces temperature for a whole year. We then collect the temperatures of the target building's surrounding surfaces from the last-round results. Finally, we run each building model taking surrounding surfaces temperature schedules and their corresponding view factors to each exterior surface.

\section{Thermal behaviors of building exterior surfaces}

In different seasons of a year and different time of a day, the amount of solar radiation received by the four facades of buildings varies. We compared the average exterior surfaces temperature in different months as shown in Figure 4. Located in the northern hemisphere, throughout the year, the surface temperature of the south façade can be $2-5^{\circ} \mathrm{C}$ higher than that of the north façade. Monthly average temperatures of the east and west facade are close during the winter season, while during summer, east façade temperature is around two degree Celsius higher.

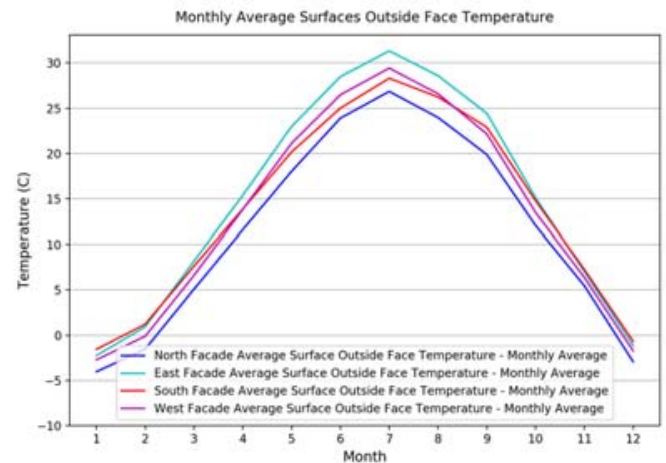

Figure 4: Monthly average exterior surfaces temperature of different facades.

In Figure 5 we picked a typical summer day and compared the hourly exterior surface temperatures. Due to the daily variation of the sun position angle along with the shading effect from surrounding buildings, the average surface temperature of different facades peaks at different time of the day.

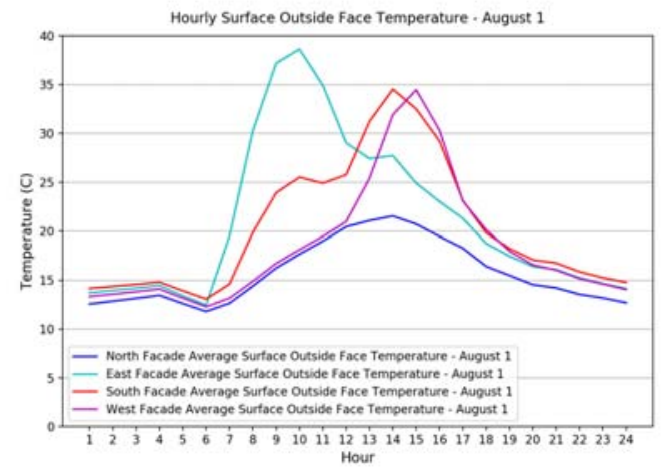

Figure 5: Daily exterior surface temperature of different facades.

This triggers the opposite directions of the surface temperature deviation from its surrounding surfaces in the studied urban area. As illustrated in Figure 6, in the morning, the surface temperature on the east façade reaches up to $20^{\circ} \mathrm{C}$ higher than the average temperature of its surrounding surfaces, while in the afternoon it can be $10^{\circ} \mathrm{C}$ lower. The west façade shows an opposite behavior. 


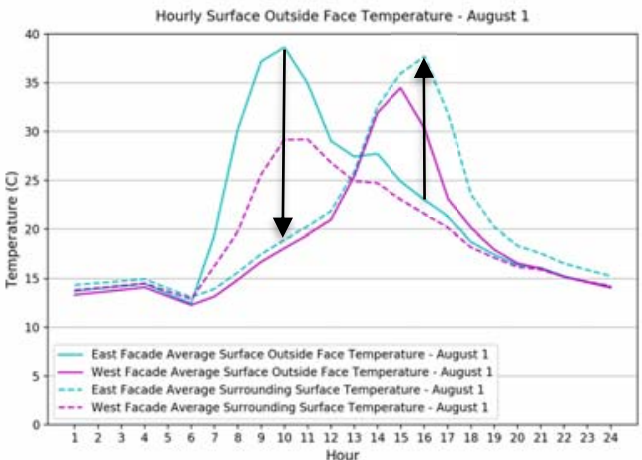

Figure 6: Surface - surrounding surface temperature difference of the east and west façade.

Figure 7 compares the behaviors of the north and south facades. With the temperature deviation, the north orientated surfaces absorb longwave radiant heat from surrounding buildings, while the south-orientated surfaces lose heat to the ambient.

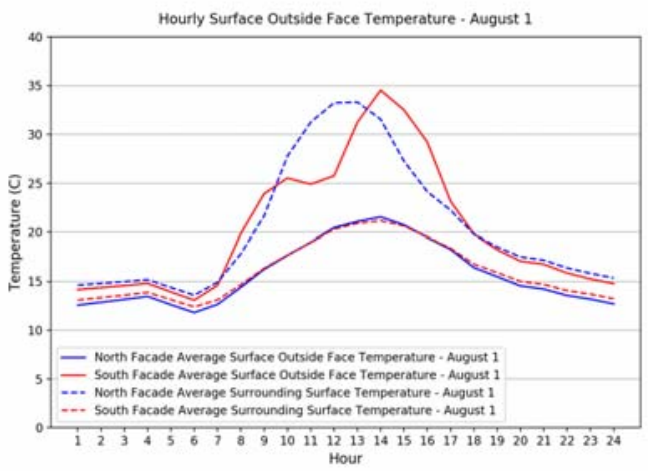

Figure 7: Surface - surrounding surface temperature difference of the north and south façade.

\section{Energy and environmental impact analysis}

For the targeted high-rise office building, considering the LWR between buildings leads to a decrease in annual heating load of $3.4 \%$, and an increase in cooling load of $2.9 \%$. The overall site energy use differs less than $0.2 \%$ and the energy impact is minimal in this case.

We further analyzed the environmental impact of the surrounding surfaces LWR effect in terms of exterior surface temperature and heat emissions to the ambient air through convection and LWR. As building exterior surfaces in EnergyPlus originally view their ambient as partial sky and partial ground, adding the LWR effects from surrounding surfaces with a much higher temperature than sky or ground, extra heat is added to surface heat balance calculation. Figure 8 demonstrates this effect of the sample simulation day, showing that the surface temperature of the north and south facades can be around $6^{\circ} \mathrm{C}$ and $3^{\circ} \mathrm{C}$ higher correspondingly considering the LWR than not.

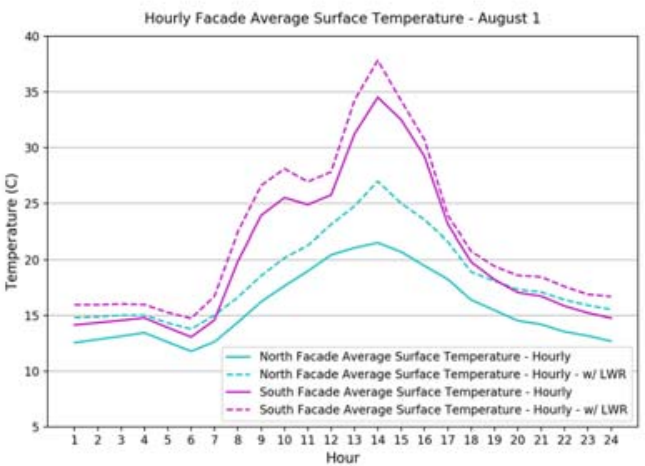

Figure 8: LWR impact to exterior surface temperature north / south façade.

Similarly, as in Figure 9, the LWR effects from surrounding surfaces facing the west façade lifts its temperature by up to $5^{\circ} \mathrm{C}$ during the day. The eastoriented surfaces are not affected as the total view factor to surrounding buildings is near-zero. It is worth considering how this deviation influences the pedestrian level thermal comfort. Moreover, served as the boundary conditions of the urban microclimate, building facades' thermal behaviors at different orientations should also be taken into consideration in detailed urban canopy models.

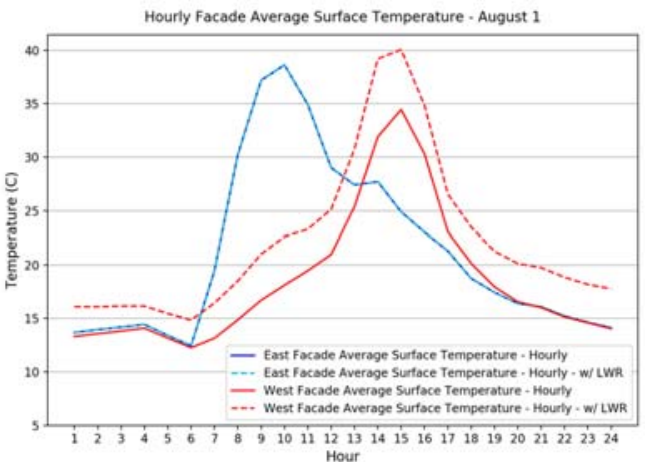

Figure 9: LWR impact on exterior surface temperature - west / east façade.

Due to the rise of the surface temperature, the heat transfer from exterior surfaces to the ambient air through convection and LWR also increases. As plotted in Figure 10 , and the difference is approximately $30 \%$ throughout the year for each month. 


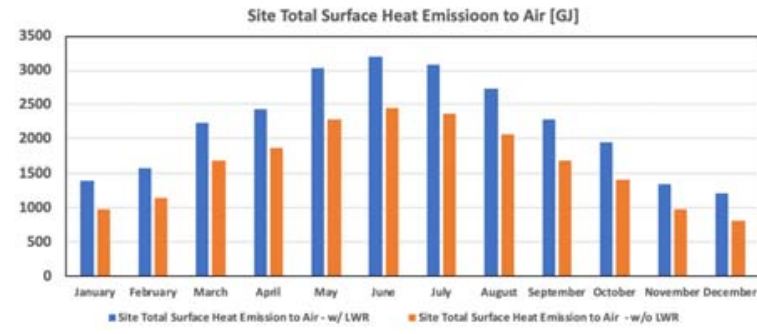

Figure 10: LWR impact on the surface heat emission to the ambient air.

\section{Conclusions}

This paper presents new features implemented in EnergyPlus version 8.8 and later to improve its use for urban context and urban scale building energy modeling by considering the longwave radiative effect between buildings' exterior surfaces. A preliminary case study was conducted within a city block in the Chicago downtown area with 20 highly dense high-rise buildings. Results indicate the temperature difference between each building façade and its surrounding surfaces with opposite orientations leads to significant radiance heat exchange between building exterior surfaces. Results also show that this temperature gap between building surfaces and their surrounding building surfaces causes the net thermal heat gain of a building from its surrounding buildings, and the heat gain induces the variations in exterior surface temperature, building loads, and energy use.

The study addresses the need of taking explicit consideration of the thermal interactions between urban surfaces in a dense urban setting with lots of high-rise buildings. More detailed simulation and quantification of the effects of building interactions at a larger scale is also needed in urban energy modeling.

\section{Acknowledgment}

This work was supported by the Assistant Secretary for Energy Efficiency and Renewable Energy, the U.S. Department of Energy under Contract No. DE-AC0205CH11231.

\section{References}

Chen, Y., Hong, T., \& Piette, M. A. (2017). City-Scale Building Retrofit Analysis: A Case Study using CityBES. In Building Simulation 2017. San Francisco, CA USA.

Cole, R. J. (1976). The longwave radiative environment around buildings. Building and Environment, 11(1), 3-13. https://doi.org/10.1016/03601323(76)90014-7

Crawley, D. B., Lawrie, L. K., Winkelmann, F. C., Buhl, W. F., Huang, Y. J., Pedersen, C. O., ..
Glazer, J. (2001). EnergyPlus : creating a newgeneration building energy simulation program, 33.

Evins, R., Dorer, V., \& Carmeliet, J. (2014). Simulating external longwave radiation exchange for buildings. Energy and Buildings, 75, 472-482. https://doi.org/10.1016/j.enbuild.2014.02.030

Gros, A., Bozonnet, E., \& Inard, C. (2014). Cool materials impact at district scale - Coupling building energy and microclimate models. Sustainable Cities and Society, 13, 254-266. https://doi.org/10.1016/j.scs.2014.02.002

Gros, A., Bozonnet, E., Inard, C., \& Musy, M. (2016). Simulation tools to assess microclimate and building energy - A case study on the design of a new district. Energy and Buildings, 114, 112122. https://doi.org/10.1016/j.enbuild.2015.06.032

Hong, T., Chen, Y., Lee, S. H., \& Piette, M. A. (2016). CityBES : A Web-based Platform to Support City-Scale Building Energy Efficiency. In Urban Computing 2016. San Francisco, San Francisco, California USA.

Hong, T., \& Luo, X. (2018). Modeling Building Energy Performance in Urban Context. In 2018 Building Performance Analysis Conference and SimBuild co-organized by ASHRAE and IBPSA-USA. Chicago, IL.

Hoover, J., \& Dogan, T. (2017). Fast and Robust External Solar Shading Calculations using the Pixel Counting Algorithm with Transparency. Building Simulation, (August), 1083-1091.

Jones, N. L. ., \& .Greenberg, D. P. (2011). Fast computation of incident solar radiation from preliminary to final building design. In 12th Conference of International Building Performance Simulation Association.

Jones, N. L., McCrone, C. J., Walter, B. J., Pratt, K. B., \& Greenberg, D. P. (2013). Automated translation and thermal zoning of digital building models for energy analysis. 13th Conference of International Building Performance Simulation Association, Chambéry, France, August 26-28, 202-209.

Li, W., Zhou, Y., Cetin, K., Eom, J., Wang, Y., Chen, G., \& Zhang, X. (2017). Modeling urban building energy use: A review of modeling approaches and procedures. Energy, 141, 2445-2457. https://doi.org/10.1016/j.energy.2017.11.071

Miller, M., \& Baker, J. W. (2016). Coupling mode- 
destination accessibility with seismic risk assessment to identify at-risk communities. Reliability Engineering and System Safety, 147(April), 60-71.

https://doi.org/10.1080/01944360208976274

UNDESA. (2014). World Urbanization Prospects.

Undesa.

https://doi.org/10.4054/DemRes.2005.12.9

Walton, G. N. (1986). Algorithms for Calculating Radiation View Factors Between Plane Convex Polygons With Obstructions. 